\title{
Desafios enfrentados pelos regimes de previdência no Brasil: o papel das premissas atuariais nos RPPS municipais
}

\author{
Pamila Cristina Lima Siviero*
}

CORRÊA, Cristiane Silva. Premissas atuariais em planos previdenciários: uma visão atuarial-demográfica. Curitiba: Appris Editora, 2018. 191 p.

O debate sobre a Previdência Social no Brasil tem se intensificado nos últimos 20 anos, especialmente em função de duas questões: o rápido processo de envelhecimento populacional e o aumento da despesa previdenciária (GIAMBIAGI et al., 2018). Desde a vigência da Constituição Federal de 1988, a busca pelo equilíbrio entre as receitas e despesas da previdência tem levado a um ambiente de conflitos e incertezas, resultando em propostas de discussões e reformas. Trata-se de um tema delicado e importante, permeado por questões sociais, financeiras, jurídicas e políticas.

A Previdência Social brasileira é dividida em três regimes: Regime Geral de Previdência Social (RGPS), de filiação obrigatória pelos trabalhadores regidos pela CLT; Regimes Próprios de Previdência Social (RPPS), de filiação obrigatória pelos servidores públicos de cargos efetivos da União, estados, Distrito Federal e municípios; e Regime de Previdência Complementar (RPC), regime privado, de filiação facultativa, cujo intuito é complementar a renda oficial do trabalhador.

\footnotetext{
*Universidade Federal de Alfenas (Unifal), Varginha-MG, Brasil (pclsiviero@gmail.com; https://orcid.org/0000-00032042-812X).
} 
No que diz respeito à previdência dos servidores públicos, atualmente existem cerca de dois mil RPPS no Brasil, distribuídos na União, em todos os estados e o Distrito Federal e nas capitais e outros municípios (CORRÊA et al., 2014). No entanto, entre os municípios, a maioria permanece no RGPS, principalmente os de pequeno porte. Entre 2005 e 2013, aproximadamente $60 \%$ dos municípios estavam vinculados ao regime geral, ao passo que os demais têm um regime próprio ativo ou em extinção (CAETANO, 2016). Um dos maiores desafios para os gestores dos RPPS e governantes, especialmente dos municípios menores, diz respeito ao equilíbrio financeiro e atuarial, o qual é alcançado quando as contribuições para o sistema são suficientes para custear os benefícios futuros assegurados pelo regime. Nesse sentido, um instrumento fundamental são as premissas atuariais, que podem ser entendidas como um conjunto de informações que estimam o comportamento futuro de diversos eventos demográficos e econômicos.

O livro Premissas atuariais em planos previdenciários: uma visão atuarial-demográfica, de autoria de Cristiane Silva Corrêa, se insere nesse debate, com foco nos desafios enfrentados pelos RPPS municipais. Didático e objetivo, o livro é dividido em três capítulos: Aspectos técnicos e teóricos da previdência brasileira; Premissas atuariais; e Premissas nos cálculos atuariais, além da introdução e considerações finais.

No primeiro capítulo, a autora discorre sobre os regimes previdenciários do Brasil, em uma perspectiva histórica, política, financeira e atuarial. Sob a ótica histórica, Corrêa inicia o capítulo diferenciando os dois regimes de previdência social do Brasil (RGPS e RPPS), bem como distinguindo as características dos RPPS da União, estados e municípios. São destacados as especificidades observadas no modelo adotado pelo país, os problemas enfrentados pelos RPPS municipais e possíveis propostas de mudanças e suas fragilidades, tais como a unificação de um regime próprio para todos os entes federativos. Essa análise é complementada por dados e informações que exemplificam com clareza as questões levantadas pela autora.

Na sequência, são elucidadas as formas de financiamento dos regimes previdenciários, como funcionam e quais são os tipos de modalidade de plano, que determinam as formas de custeio. Em conjunto com a apresentação dos conceitos, Corrêa traz o debate da literatura sobre a mudança do regime financeiro de repartição simples para capitalização, sendo este um ponto alto do livro.

Finalizando o primeiro capítulo, é apontada a importância das premissas atuariais, que são fundamentais para o equilíbrio dos planos previdenciários nos quais o benefício que será recebido futuramente é conhecido a priori. Nessa seção, são destacadas as fragilidades resultantes das escolhas das premissas, outro ponto alto do texto: muitas vezes, as escolhas são pautadas por motivações políticas e financeiras, especialmente em tempos de recursos escassos. Nesse sentido, a autora aponta para o fato de que, em alguns casos, a legislação permite a adoção de premissas pouco realistas para inibir o déficit atuarial. Ademais, no campo político, como o efeito de manipulação de premissas será sentido apenas pelas gerações futuras, utilizar os recursos dos planos previdenciários públicos pode parecer uma alternativa de aumentar a chance de reeleição. A autora reforça 
que a escolha das premissas atuariais deveria refletir as funções que se espera observar futuramente na população em estudo e que o grande desafio é determinar quais são as funções mais verossímeis, uma vez que não há orientação clara na literatura para pautar a decisão. Corrêa indica alguns caminhos para auxiliar na escolha das premissas, por meio de trabalhos e estudos que o fizeram e também as fragilidades apontadas nesses textos. Idealmente, as premissas atuariais deveriam ser estimadas com dados da própria população de interesse. No entanto, como nem sempre tais informações estão disponíveis - o que frequentemente acontece em populações pequenas -, outras bases de dados podem ser utilizadas para auxiliar esse processo de decisão, lembrando sempre que os dados escolhidos afetam os resultados encontrados, bem como a importância de se conhecer, minimamente, a dimensão dos erros associados.

Mesmo que as premissas atuariais sejam adequadas, o tamanho reduzido das populações tende a afetar os resultados dos cálculos atuariais. Como os planos de benefício previdenciário são permeados por muita incerteza, a autora termina o capítulo apresentando maneiras e modelos adotados para lidar com a variabilidade apresentada pelas funções econômicas e demográficas, tais como modelos de Asset Liabiity Management (ALM), modelos de ruína e de microssimulações. Corrêa expõe brevemente os modelos e suas diferenças, destacando a relevância da análise dos riscos associados, de forma a garantir a solvência e saúde dos planos previdenciários.

No segundo capítulo são apresentadas as premissas atuariais. Para algumas, os valores das funções já estão disponíveis, como por exemplo as tábuas de mortalidade e de entrada em invalidez. Para premissas que não possuem função definida, o texto versa sobre os métodos de estimação que podem ser utilizados. As premissas atuariais são divididas em econômicas e demográficas. Entre as primeiras, foram analisadas a rentabilidade e a taxa de crescimento de remuneração. As demográficas foram divididas em decrementais (mortalidade, invalidez, aposentadoria e exoneração) e outras (idade de entrada, ter cônjuge, ter filho, idade do cônjuge e idade do filho).

A primeira parte do capítulo é dedicada a investigar a composição populacional dos trabalhadores por sexo, idade e rendimentos, com dados da PNAD 2011, focando nos servidores municipais e diferenciando-os dos demais trabalhadores. 0 objetivo é entender as características da população, no intuito de definir as premissas em uma análise atuarial. Na sequência, é apresentada, analisada e discutida de forma bem detalhada cada uma das premissas demográficas e econômicas. Essa é uma grande contribuição do livro: diante da lacuna da literatura nacional sobre premissas atuariais, Corrêa faz um ótimo trabalho de organizar, revisar, discutir e apontar caminhos para pautar a escolha de cada uma das premissas, embasada na literatura internacional e também nos trabalhos que já foram realizados no Brasil, fundamentais nesse contexto. As tábuas utilizadas neste capítulo são apresentadas no anexo do livro, o que permite o uso em outros estudos atuariais.

No último capítulo do livro, a autora avalia o impacto de variações de cada uma das premissas nos cálculos atuariais, por meio de mudanças nos valores das alíquotas de 
contribuição. 0 exercício é realizado da seguinte maneira: Corrêa adota um método de custeio (Custo Acumulado Proporcional ao Salário), apresenta os pressupostos, define um conjunto de premissas atuariais e estima o custeio de um plano previdenciário hipotético. Em seguida, por meio de exercícios contrafactuais, cada uma das premissas é alterada e o resultado comparado com o modelo inicial estimado. Assim, de forma muito didática, é possível observar como mudanças nos valores das premissas atuariais afetam o custeio de um plano de previdência.

Embora o livro seja focado para RPPS de servidores municipais, recorte escolhido pela autora, os achados permitem elucidar questões relacionadas não apenas a esse subgrupo populacional, mas também àqueles vinculados aos Regimes Geral, Complementar e Privados. Dessa forma, o livro é uma referência para estudantes, professores, profissionais e interessados na temática, podendo ser utilizado como material didático de qualidade para cursos de graduação e pós-graduação em Ciências Atuariais e também pelos gestores de planos de RPPS, uma vez que trata as premissas de uma forma didática e elucidativa. Finalmente, a obra traz outras importantes contribuições, apontando como alguns fatores, tais como as limitações dos dados, alterações na legislação e incorporação de tendências futuras de variáveis como a mortalidade, podem afetar os cálculos e análises atuariais.

\section{Referências}

CORRÊA, C. S.; QUEIROZ, B. L.; RIBEIRO, A. J. F. Tamanho populacional e custeio previdenciário: como variações aleatórias afetam o risco de solvência de RPPS municipais. Redeca - Revista Eletrônica do Departamento de Ciências Contábeis \& Departamento de Atuária e Métodos Quantitativos, v. 1, n. 1, p. 128-149, 2014.

CAETANO, M. A.-R. Solvência fiscal de longo prazo dos regimes próprios de previdência dos estados e municípios. Brasília: Ipea, 2016. (Texto para Discussão, 2195).

GIAMBIAGI, F.; PINTO, F.; ROTHMULLER, L. Reforma previdenciária em 2019: elementos para uma tomada de decisão. Brasília: BNDES, out. 2018. (Texto para discussão, 127).

\section{Sobre a autora}

Pamila Cristina Lima Siviero é mestre e doutora em Demografia pelo Centro de Desenvolvimento e Planejamento Regional (Cedeplar), da Universidade Federal de Minas Gerais (UFMG). Professora do Instituto de Ciências Sociais Aplicadas da Universidade Federal de Alfenas.

\section{Endereço para correspondência}

Avenida Celina Ferreira Otoni, 4000, Bairro Padre Vitor

37048-395 - Varginha-MG, Brasil 